\title{
EFFECT OF INJECTOR OPENING PRESSURE ON PERFORMANCE AND EMISSION OF LPG - METHYL ESTER OF MAHUA OIL DUAL FUEL ENGINE
}

\author{
N. Kapilan* \\ Research Scholar, Department of Mechanical Engg, \\ National Institute of Technology Karnataka, Mangalore, India
}

Received 07 August 2006

\begin{abstract}
One of variables, which affect the performance and emission of dual fuel engine is injection pressure. Hence in the present work, effect of Injector opening pressure on the performance of the engine was studied. A four stroke single cylinder engine was modified to work in dual fuel mode. Three injector opening pressures (180 bar, 200 bar and 220 bar) were considered for the present work. Methyl ester of mahua oil was used as pilot fuel and LPG was used as primary fuel.

From the test results, it was observed that the injector opening pressure of 200 bar results in higher brake thermal efficiency. The higher injector opening pressure results in better atomization and peneatration of methyl ester of mahua oil. The exhaust emissions such as Smoke, unburnt hydro carbon and carbon monoxide of 200 bar is lower than other pressures.
\end{abstract}

Nomenclature: MEMO - Methyl Ester of Mahua Oil; BSEC - Brake Specific Energy Consumption; EGT - Exhaust Gas Temperature.

Keywords: Alternative fuel, LPG, Biodiesel, Dual fuel engine, Performance, Emission

\section{INTRODUCTION}

During recent years high activities can be observed in the field of Alternative fuels, due to supply of petroleum fuels strongly depends on a small number of oil exporting countries. As far as low emission fuels are concerned, "gaseous fuels" appear to be capable of performing a prominent role. Various gaseous fuels such as biogas, producer gas, hydrogen, LPG (Liquefied Petroleum Gas) and CNG (Compressed Natural Gas) are suitable for Internal Combustion Engines. But LPG and CNG are considered better alternatives because of their simpler structure with low carbon content, resulting in reduction of exhaust emissions drastically. In India, LPG is easily available compared to CNG. Hence, for the present work LPG is taken as gaseous fuel. Since diesel is a non-renewable fuel, biodiesel can be used as substitute for diesel in dual fuel mode. In dual fuel engine, the primary fuel releases large amount of energy and secondary fuel or pilot fuel is required to start the combustion of the primary fuel.

Karim [1] have made comprehensive studies of combustion phenomena in gas fuelled single cylinder diesel engines, mostly DI diesel engine. He observed that LPG results in poor performance at light loads. It was found that $\mathrm{CO}$ and UBHC concentrations increased rapidly at light loads compared to those normally measured in diesel engines, with propane having higher

* Corresponding author e-mail: kapil_krecmech@yahoo.com 
concentration than methane. Karim attributed this to the fact that the ignition delay period of the pilot diesel fuel is much higher during propane fumigation than that with methane. Beyond half load, however, efficiency improved and surpasses that of diesel fuel at full load. Here, propane was found to be a better fuel than methane. He also noted that a reduction in peak cylinder pressure, fumigation of methane and propane produced lower concentration of NOx, particularly at higher loads. Poonia et al [2] studied the effect of intake air temperature and pilot fuel quantity on the combustion characteristics of a LPG Diesel dual fuel engine. They considered pilot quantities of 3.36, 4.6, 5.9, 7.5, 8.4 and $10.7 \mathrm{mg} /$ cycle and the compression ratio of 15:1.

Sethi et al [3] studied the performance and emission of LPG - Diesel dual fuel engine. They reported that the dual engine performance is comparable with diesel (sole fuel) operation at higher loads. But oxides of nitrogen emissions were higher than neat diesel operation. They also reported that the exhaust emissions such as carbon monoxide, un burnt hydrocarbon and sulfur dioxide emissions were reduced by $80 \%, 71 \%$ and $21 \%$ respectively.

Hitoshi [4] studied the combustion phenomena and ignition characteristics by visualizing the combustion chamber while the engine is operated under the dual combustion mode. They used an open chamber type single cylinder research engine together with an endoscope suitable for observing a small space. From the experimental results they observed that the pilot fuel is ignited around the nozzle tip due to less penetration of pilot fuel. After pilot fuel is auto ignited, the pilot flame propagates to the lean gas pre mixture rapidly. They also reported that the ignition delay and combustion intensity of pilot fuel is influenced by partial pressure of oxygen in the fresh air when injection condition and compression end temperature are kept constant.

Weidong et al [5] used Pilot Diesel Injection in an HCCI (PDI-HCCI) engine to decrease the required intake temperature. A small amount of diesel was injected into the cylinder early in the compression stroke for a natural gas fuelled HCCI engine. They found that the PDI-HCCI concept can reduce the required initial temperature by about $70 \mathrm{~K}$ compared to the conventional HCCI engine. They also found that the performance of the HCCI engine became less sensitive to initial temperatures in the PDI-HCCI combustion process compared to the conventional HCCI engine case.

Mohanan et al [6] studied the effect of cycle variation on the performance of the LPG-Diesel dual fuel engine. They found that for LPG flow rates between 0.2 to $0.3 \mathrm{~kg} / \mathrm{hr}$ fluctuations in various parameters like peak pressure, rate of pressure rise and indicated mean effective pressure is minimum, because the combustion is mainly due to diesel fuel and relative lean mixture of diesel and air burns efficiently. At LPG flow rate beyond $0.3 \mathrm{~kg} / \mathrm{hr}$ the fluctuations in performance parameters increase due to the fact that combustion is not efficient because mixture being very lean. But the best result is obtained at flow rates between 0.5 to $0.5 \mathrm{~kg} / \mathrm{hr}$. They concluded that at full load fluctuations in indicated mean effective pressure, indicated thermal efficiency and peak pressure remains steady state at low value for most of the LPG flow rates.

Kapilan et al [7] studied the performance and emission of a LPG - Biodiesel dual fuel engine. They used methyl ester of sunflower oil as pilot fuel and LPG as primary fuel. They reported that the performance and emission of the dual fuel engine is comparable with diesel engine at higher loads.

Sukumar et al [8] used methyl ester of mahua oil as sole fuel in diesel engine. They Prepared Mahua Oil Ethyl Ester (MOEE) by transesterfication method using sulfuric acid $\left(\mathrm{H}_{2} \mathrm{SO}_{4}\right)$ as catalyst and MOEE was tested in a 4-stroke direct injection natural aspirated diesel engine. Tests were carried out at constant speed of $1500 \mathrm{rev} / \mathrm{min}$. They reported that the performance of MOEE was comparable with diesel operation and emissions such as carbon monoxide, hydrocarbons, oxides of nitrogen and smoke were lower than diesel operation. 


\section{PRESENT WORK}

From the literature review, it is observed that no work has been done to use Methyl Ester of Mahua Oil (MEMO) as pilot fuel in dual fuel engine. Hence in the present work, MEMO was used as pilot fuel in dual fuel engine and the effect of injector opening pressure on the performance and emission of the dual engine was studied. The injector opening pressure recommended for diesel operation is 180 bar. Since the viscosity of MEMO was higher than diesel, higher pressures such as 200 bar and 220 bar were considered for the present work. A single cylinder diesel engine was modified to work in dual fuel mode.

\section{EXPERIMENTAL SETUP}

A single cylinder four stroke water cooled naturally aspirated direct injection diesel engine was modified to work in dual fuel mode. The engine details are given in Table 1. Photo 1 shows the experimental setup.

Table 1: Engine Details.

\begin{tabular}{ll}
\hline Engine & $4-\mathrm{S}$, Single cylinder, water cooled engine \\
Make/Model & Kirloskar TV 1 \\
BHP & 7 BHP @ 1500 RPM \\
Bore $\times$ Stroke & $87.5 \times 110 \mathrm{~mm}$ \\
Compression Ratio & $17.5: 1$ \\
Injection Timing & $27^{\circ} \mathrm{b}$ TDC \\
\hline
\end{tabular}

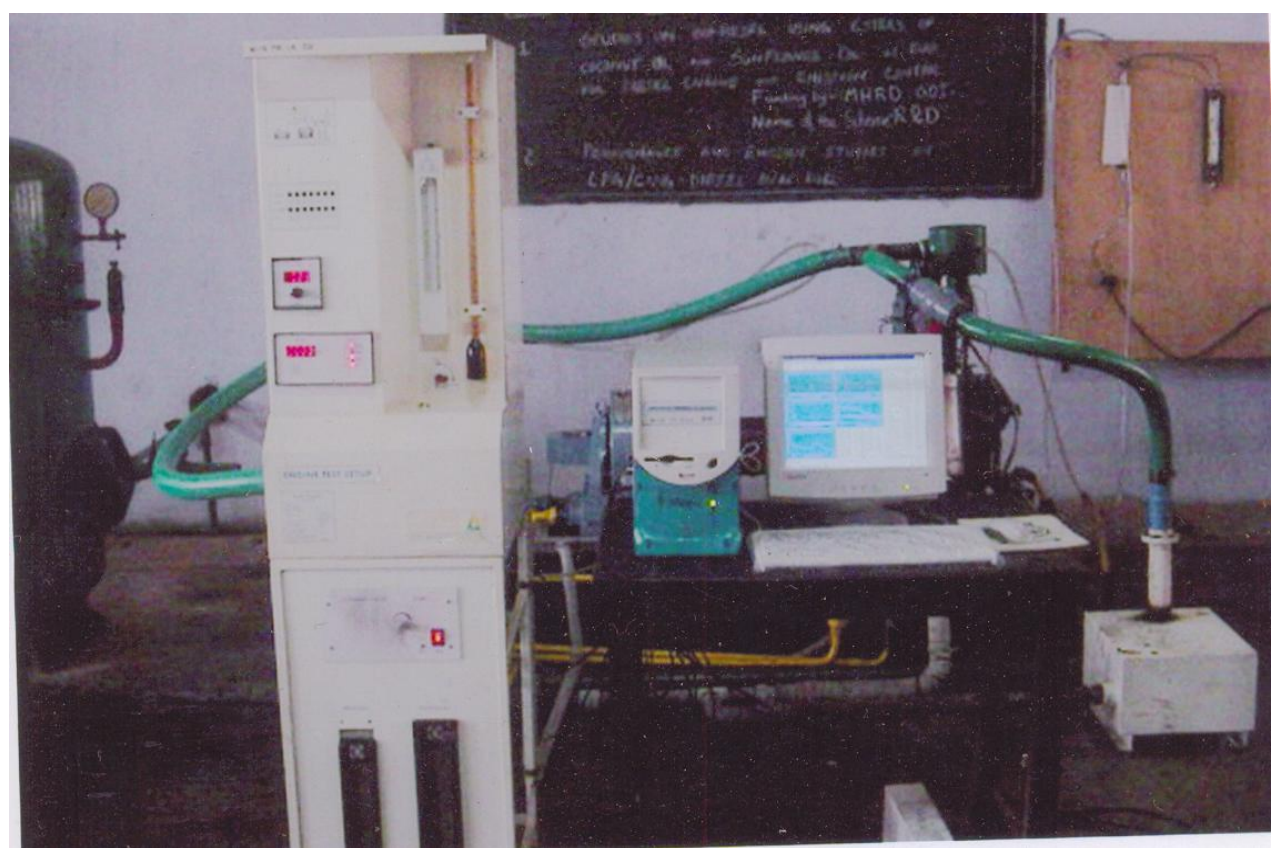

Photo 1: Experimental Setup. 
A single cylinder four stroke water cooled naturally aspirated direct injection diesel engine was modified to work in dual fuel mode. This modified duel fuel engine is a computerized dual fuel engine test rig and it was used for the experimental work. An eddy current dynamometer was used for loading the engine. The engine speed was sensed and indicated by an inductive pick up sensor in conjunction with a digital rpm indicator, which is a part of eddy current dynamometer. The diesel fuel flow rate was measured on the volumetric basis using a burette and a stopwatch. Chromel alumel thermocouple in conjunction with a digital temperature indicator was used for measuring the exhaust gas temperature. The gas flow rate was measured using a rotameter with duralumin float. A AVL make smote meter was used for the measurement of smoke.

\section{EXPERIMENTAL PROCEDURE}

For the present work, experiments were conducted at the speed of $1500 \mathrm{rpm}$ and the compression ratio of 17.5:1. The engine was started by hand cranking with diesel as fuel. The cooling water flow rate to the cooling jacket was maintained at $300 \mathrm{lts} / \mathrm{hr}$. Experiments were conducted at the injection timing of $27^{\circ} \mathrm{bTDC}$ and the injection pressure of $180 \mathrm{bar}$. Engine is started with MEMO as fuel and slowly LPG is introduced to the cylinder through air intake manifold. At steady state condition, important observations such as liquid fuel flow, gas flow, air flow, exhaust gas temperature, cylinder pressure and smoke emission were recorded. Then the load is gradually increased and observations were recorded for the different loads. The same procedure was repeated for higher injector opening pressures such as 200 bar and 220 bar.

\section{RESULT AND DISCUSSION}

Engine was smoothly running with the injector opening pressure of 200 bar. But knocking was observed at other injector opening pressures. The performance and emissions of the dual fuel engine are presented and discussed below.

Figure 1- 5 shows the variation of cylinder pressure with load at different injector opening pressures.

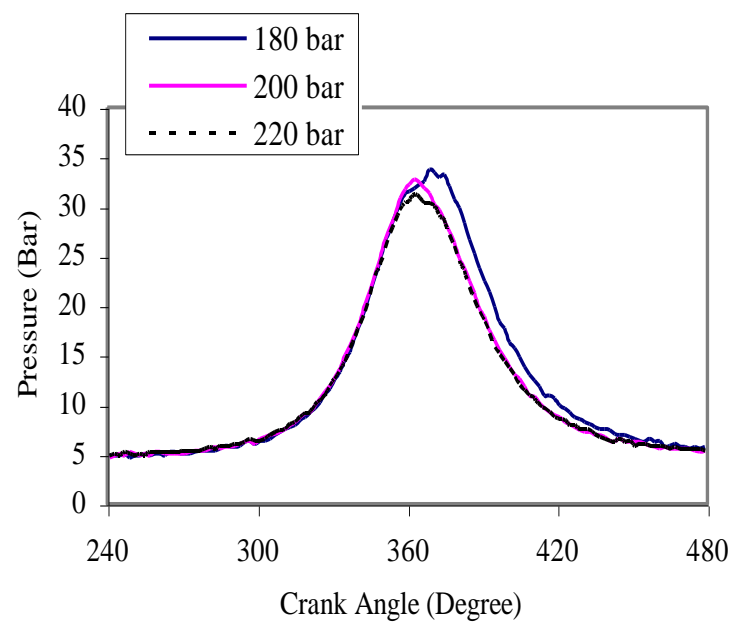

Fig. 1: Pressure vs crank angel at no load.

At no load condition, the injection pressure of 180 bar results in higher pressure rise. This may be due to poor penetration of the pilot fuel, which results in accumulation of fuel nearer to the 
injector. This results in delay in combustion of the LPG. The sudden combustion of the LPG results in higher pressure rise. At $25 \%$ load, 220 bar results in higher pressure rise than other pressures. A slight variation in pressure was observed at $50 \%$ load. At $75 \%$ and full loads, 180 bar results in pressure rise after top dead center. This shows that, late burning of fuel and hence knocking is developed. There is a slight variation in pressure rise between 200 bar and 220 bar pressures.

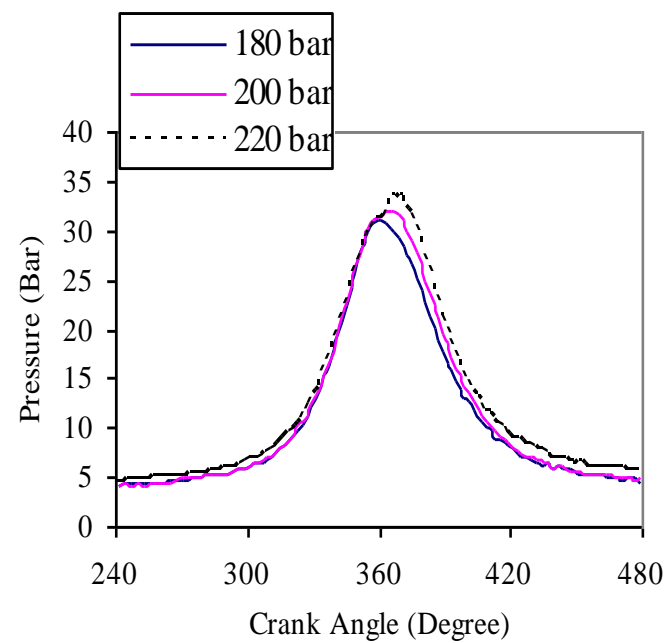

Fig. 2: Pressure vs crank angel at 25\% load.

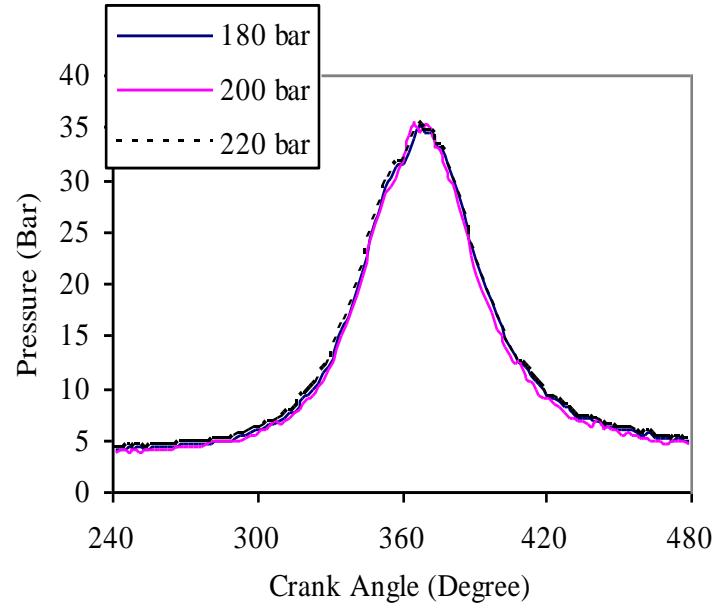

Fig. 3: Pressure vs crank angel at 50\% load.

Figure 6 shows the variation of brake thermal efficiency at different injector opening pressures. From the figure it is observed that the injector opening pressure of 200 bar results in higher brake thermal efficiency than other pressures. This may be due to better combustion of the fuel and pressure crank angle diagram also shows the same trend. The injector opening pressure of 
180 bar results in lower efficiency at higher loads. This may be due to poor atomization and penetration of pilot fuel.

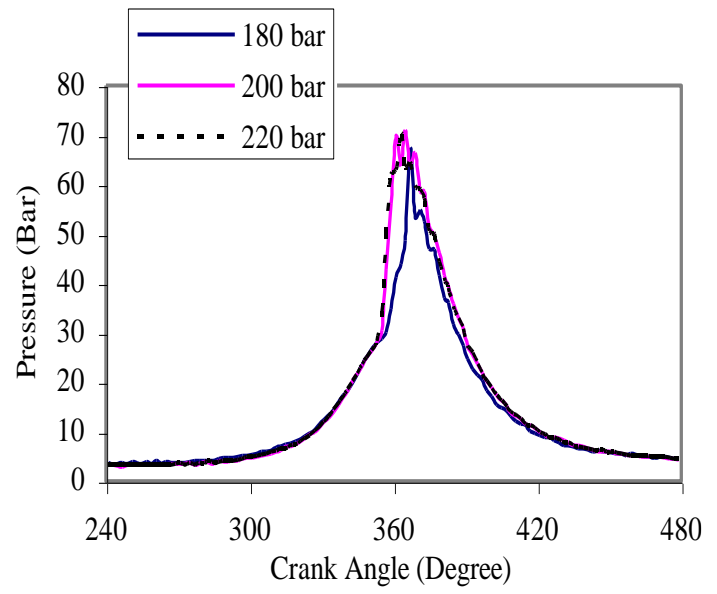

Fig. 4: Pressure vs crank angel at $75 \%$ load.

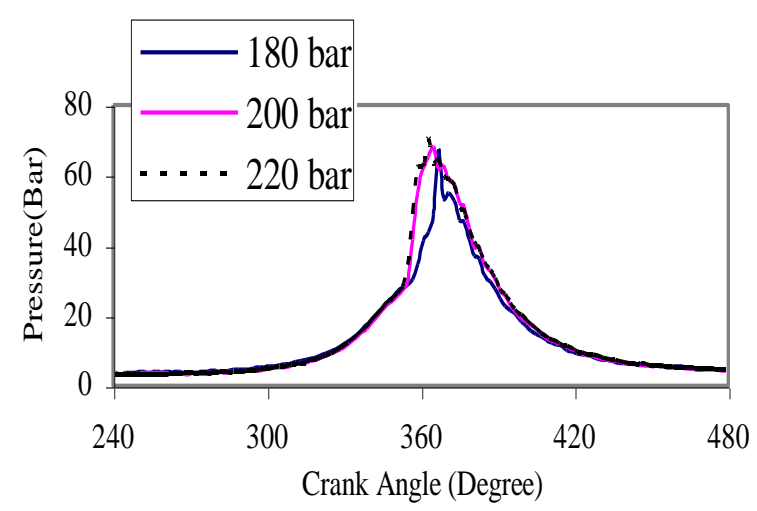

Fig. 5: Pressure vs crank angel at full load.

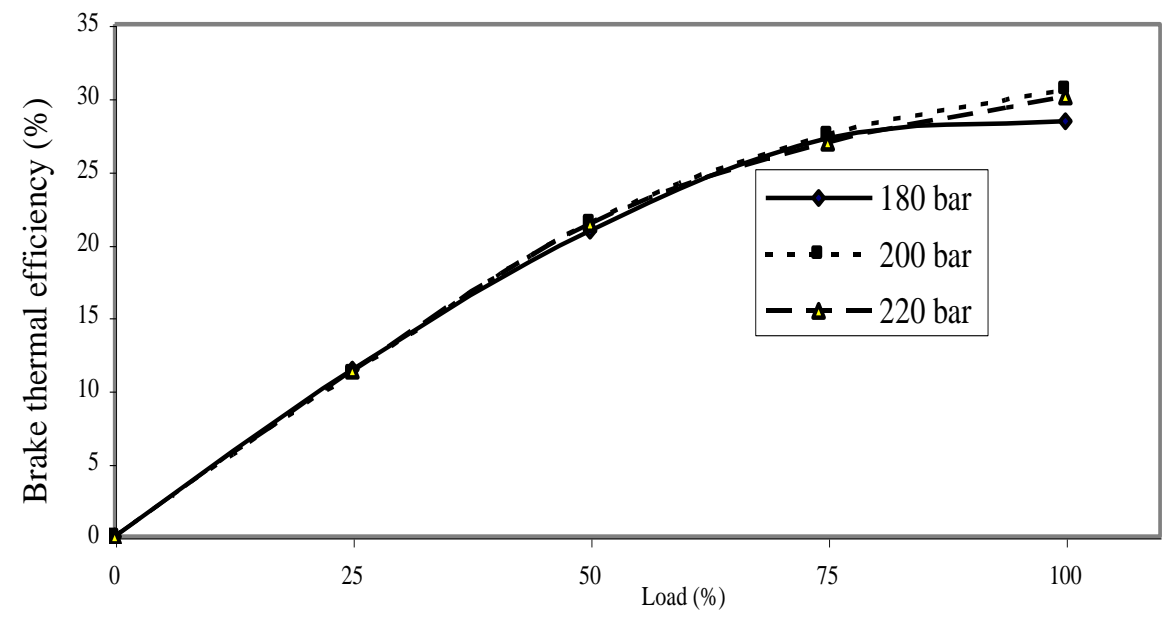


Fig. 6: Brake thermal efficiency vs load.

The variation of Brake Specific Energy Consumption (BSEC) with load is shown in Fig.7. At low loads, there is a slight variation in BSEC. But as the load increases, BSEC also varies. The injector opening pressure of 180 requires higher energy at full load due to poor combustion of the fuel.

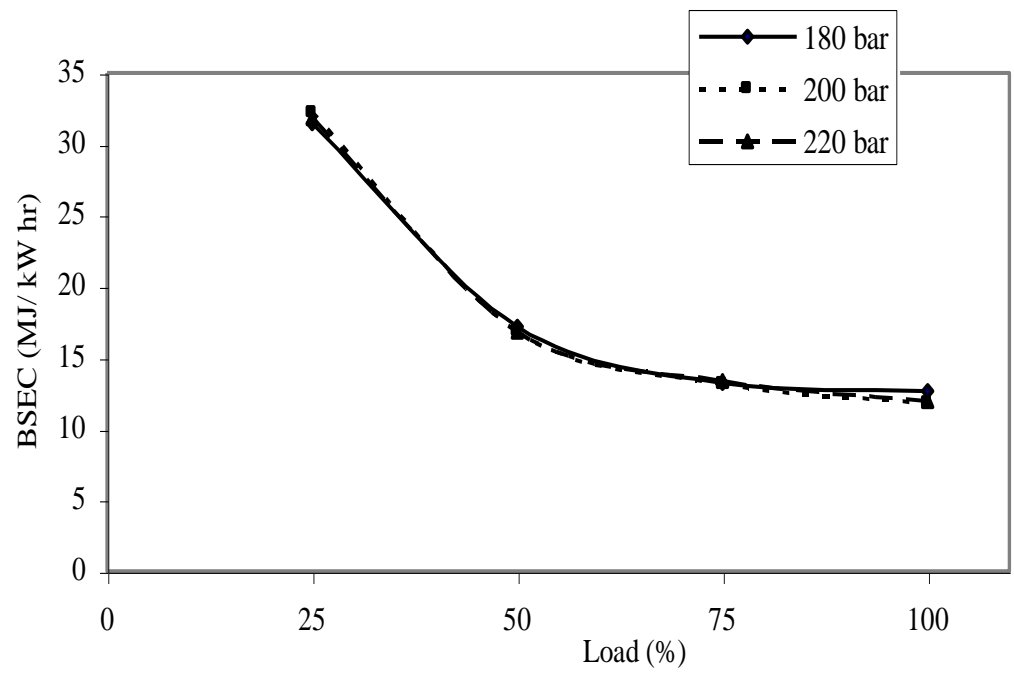

Fig. 7: BSEC vs load.

The variation of Exhaust Gas Temperature (EGT) with load at different injector opening pressure is shown in Fig.8. At higher loads, the injector opening pressure of 200 bar results in higher EGT. This may be due to the better combustion of the fuel and hence higher combustion temperature. This higher combustion temperature results in higher EGT.

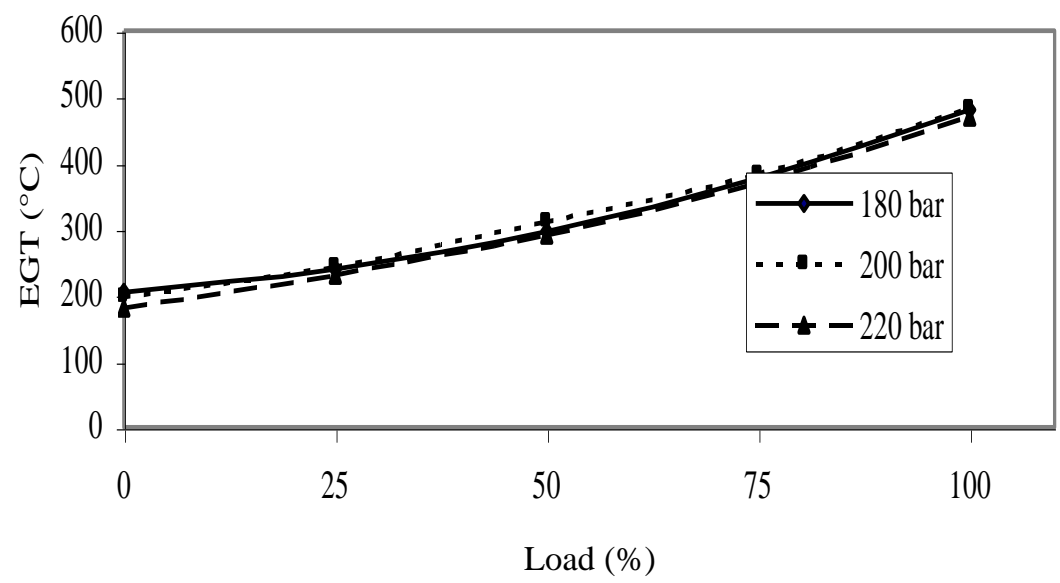

Fig. 8: EGT vs load.

Figure 9 shows the variation of smoke emission with load at different injector opening pressures. From the figure it is observed that the injector opening pressure results in higher 
smoke emission. This is due to poor combustion of the fuel. The injector opening pressure of 200 bar results in lower smoke emission.

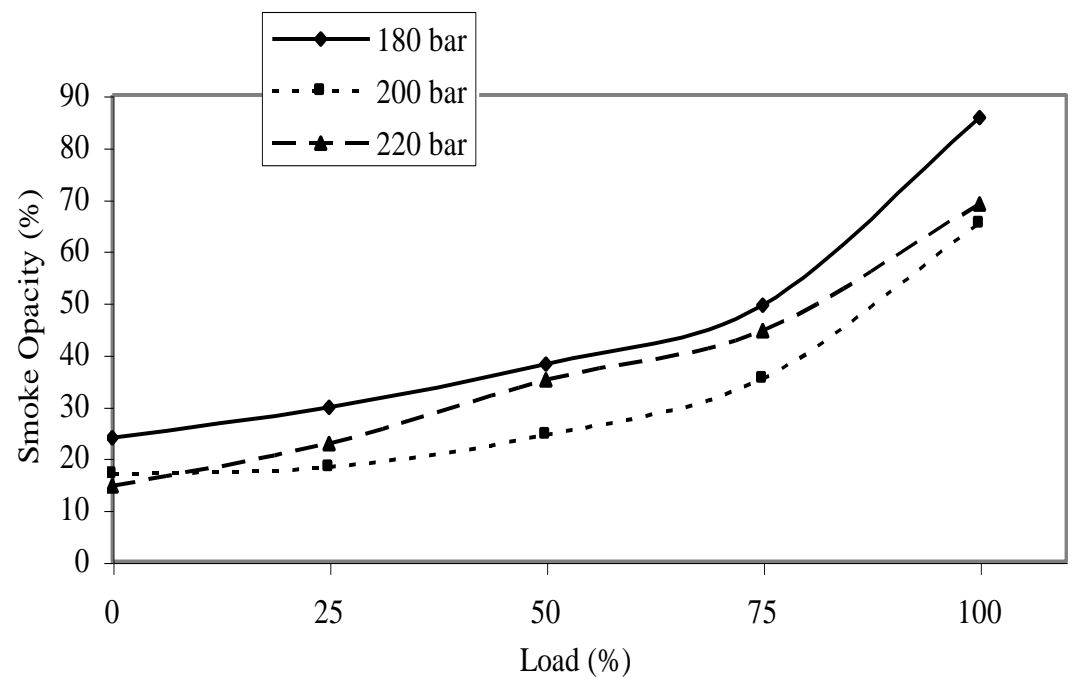

Fig. 9: Smoke vs load.

The variation of carbon monoxide (CO) emission with load at different injector opening pressure is shown in Figure 10. At low loads, there is a slight variation in $\mathrm{CO}$ emission at different injector opening pressures. At higher loads, the injector opening pressure of 180 bar results in higher $\mathrm{CO}$ emission due to incomplete combustion of the fuel. But the injector opening of 200 bar results in lower CO emission than other pressures at higher loads.

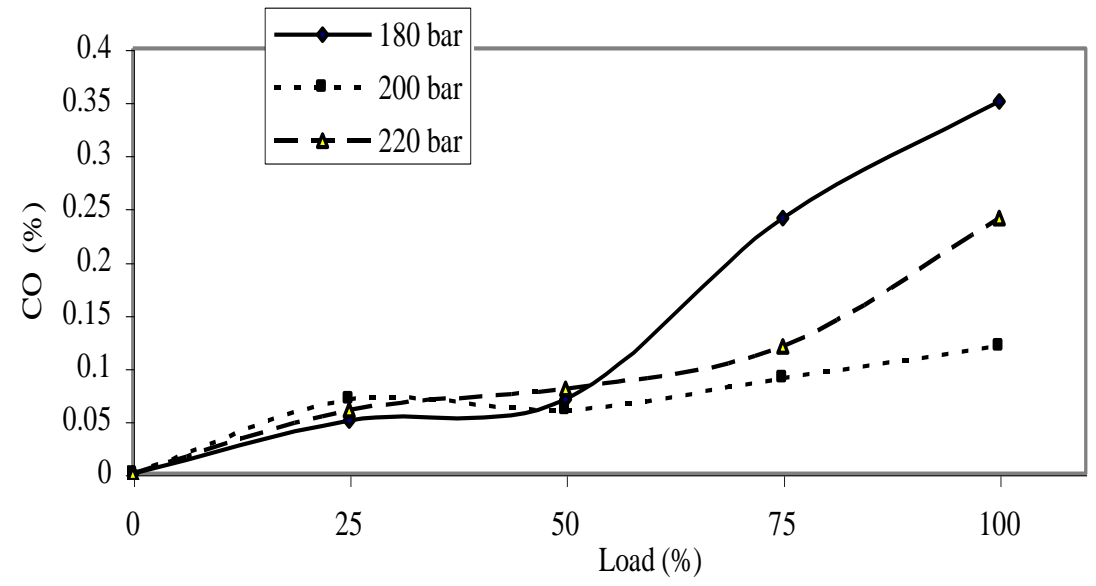

Fig. 10: Brake thermal efficiency vs load.

\section{CONCLUSIONS}

From the test results, the following conclusions are drawn.

1. Injector Opening pressure of 200 bar results in higher brake thermal efficiency. 380 
2. Injector opening pressure of 180 bar results in poor combustion and knocking.

3. Low smoke and $\mathrm{CO}$ emissions where observed at the injector opening pressue of 200 bar.

4. Higher exhaust gas temperature was observed with the pressure of 180 bar.

\section{ACKNOWLEDGEMENT}

The financial help provided by TEQIP, for this on going project is greatly acknowledged. Authors also thank Mr.Micheal, Foreman, Fuel Laboratory and Mr.Bhoja, Senior Mechanic, Engine Laboratory, NITK, Surathakal, for their help during experimental work.

\section{REFERENCES}

1. Ghazi A Karim (1980, A review of combustion process in the dual fuel engine - the gas diesel engine, Journal for Progress Energy Combustion Science, Pergamon Press Ltd. Vol. 6, pp. 277-285,

2. Poonia, M.P., Ramesh, A., and Gaur, R.R. (1988), Effect of intake air temperature and pilot fuel quantity on the combustion characteristics of a LPG Diesel Dual Fuel Engine, Journal of SAE, paper no 982455.

3. Sethi, V.P. and Salariya, K. S. (2004), Exhaust analysis and performance of a single cylinder diesel engine run on dual fuels. Journal of Institute of Engineers (India), Vol 85, pp. 1-7.

4. Hitoshi Saito, Sakurai, Sakonji, Hirashima, and Kanno (2001), Study on lean gas engine using pilot oil as the ignition source, Journal of SAE, paper no 2001- 01 - 0143.

5. Weidong Gong, Stuart R. Bell, Gerald J. Micklow, Scott, and Martin (2002), Using Pilot diesel injection in a natural gas fueled HCCI Engine", SAE Journal, paper no 2002-012866.

6. Mohanan, P., Shrinivasa Rao, and Suresh Bekal (2003), Some experiments on a dual fuel diesel engine with injection of vegetable oils and induction of LPG, Proceedings of 26th National Renewable energy convention of solar energy society of India and international conference on new millennium - alternative energy solutions for sustainable development pp. 480-485, 17-19, PSG College of Engineering Coimbatore, India.

7. Kapilan, N., Reddy, R.P., and Mohanan, P. (2004), Studies on Esters of Sunflower oil as fuel for LPG -Biodiesel Dual fuel Engine, Paper No F2004V104, VII FISITA 2004 World Automotive Congress, Barcelona, May 23-27.

8. Sukumar Puhan, Vedaraman, N., Sankaranarayanan, G., and Boppana, V. Bharat Ram, (2005), Performance and emission study of Mahua oil ethyl ester in a 4-stroke natural aspirated direct injection diesel engine, Journal of Renewable Energy, Volume 30, Issue 8 pp. $1269-1278$

9. Heywood, J.B. (1988), Internal Combustion Engine Fundamentals", McGraw Hill, NewYork. 